\title{
Beberapa Graf Khusus Dari Grup Quaternion
}

\author{
Abdul Gazir Syarifudin. , I Gede Adhitya Wisnu Wardhana ${ }^{b, *}$ \\ aUniversitas Mataram, Jl.Majapahit 62, Mataram, 83125, Indonesia. Email:abdgazirsyazir@gmail.com \\ bUniversitas Mataram, Jl.Majapahit 62, Mataram, 83125, Indonesia. Email: a adhitya.wardhana@ unram.ac.id
}

\begin{abstract}
A B S T R A C T
Research on an algebraic structure represented in graph theory opens the way for new research in recent years. Several types of new graphs continue to be developed, such as coprime and non-coprime graphs. This article will represent the quaternion group in several graphs, such as coprime graphs, non-coprime graphs, commuting graphs, non-commuting graphs, and identity graphs. We obtained several theorems about unique graphs. One of the results is that non-coprime graphs from the quaternion group are complete and regular graphs.
\end{abstract}

Keywords: quaternion group, special graph, complete graph, regular graph.

\begin{abstract}
A B S T R A K
Penelitian pada struktur aljabar yang direpresentasikan dalam teori graf membuka jalan munculnya penelitian baru pada beberapa tahun terakhir. Beberapa jenis graf baru terus dikembangkan seperti graf koprima dan non-koprima. Dalam artikel ini, grup quaternion akan direpresentasikan dalam beberapa graf seperti graf koprima, graf nonkoprima, graf commuting, graf non-commuting dan graf identitas. Didapatkan beberapa teorema tentang graf khusus salah satunya adalah bentuk graf non-koprima dari grup quaternion adalah graf lengkap dan teratur.
\end{abstract}

Keywords: Grup quaternion, Graf khusus, Graf lengkap dan teratur. Diserahkan: 13-06-2020; Diterima: 30-06-2021; Doi: https://doi.org/10.29303/emj.v1i1.74

* Corresponding author.

Alamat e-mail: adhitya.wardhana@unram.ac.id 


\section{Pendahuluan}

Dalam ilmu matematika terdapat banyak cabang, diantaranya teori graf dan teori grup. Teori graf merupakan pokok bahasan yang sudah tua usianya namun memiliki banyak terapan sampai saat ini. Graf digunakan untuk mempresentasikan objek-objek diskrit dan hubungan antara objek-objek tersebut. Representasi visual dari graf adalah dengan menyatakan objek sebagai simpul atau titik, sedangkan hubungan antara objek dinyatakan dengan garis. Grup quaternion adalah salah satu grup yang menarik untuk dibicarakan. Pada tahun 2019, Syarifudin dan Wardhana telah memberikan beberapa sifat pada grup quaternion antara lain yaitu komutatif, subgrup, orde hingga pembangunnya. Dari sifat-sifat yang diperoleh kemudian dikembangkan untuk melihat beberapa graf representasi dari grup quaternion, seperti graf koprima, graf non-koprima, graf commuting, graf non-commuting dan graf identitas.

Beberapa studi terdahulu oleh beberapa penulis telah memberikan hasil pada studi graf koprima dari beberapa grup seperti grup bilangan bulat modulo (Juliana dkk, 2020), grup dihedral (Syarifudin dkk, 2021), dan grup generalized quartenion (Nurhabibah dkk, 2021). Demikian juga beberapa penulis juga memberikan hasil pada graf non-koprima dari beberapa grup seperti grup bilangan bulat modulo (Masriani dkk, 2020), dan grup dihedral (Misuki dkk, 2021).

Berikut definisi dan teorema yang mendasari penelitian ini.

Definisi 1.1(Fraleigh, 2014)

Grup $G$ adalah sebuah sistem aljabar yang terdiri atas suatu himpunan tak kosong $G$ dan suatu operasi biner (*) yang didefinisikan pada $G$ serta memenuhi aksioma-aksioma berikut ini:

1. Untuk setiap $a, b \in G$ berlaku $a * b \in G$.

2. Operasi*bersifatassosiatif, yaitu $a * b * c=(a *$ b) $* c$, untuk setiap $a, b, c \in G$.

3. Terdapat elemen identitas $e \in G$ sedemikian sehingga $a * e=e * a=a$, untuk setiap $a \in G$.

4. Untuk setiap $a \in G$, terdapat elemen $a^{-1} \in G$ sedemikian sehingga $a * a^{-1}=a^{-1} * a=e$.
Untuk selanjutanya, Grup $G$ dengan operasi * disimbolkan dengan $(G, *)$, dan pada artikel ini hanya akan ditulis grup $G$.

Suatu grup $G$ dikatakan grup abelian atau komutatif jika operasi binernya bersifat komutatif.

Definisi 1.2(Romdhini, dkk., 2016)

Jika $(G, *)$ suatu grup yang memenuhi sifat komutatif, yaitu untuk setiap $a, b \in G, a * b=b * a$, maka $(G$,* ) disebut grup komutatif atau grup abelian.

Suatu subhimpunan tak kosong $H$ dari grup $G$ membentuk suatu subgrup dari $G$ bila subhimpunan $H$ juga membentuk grup dengan operasi yang sama pada $G$.

Definisi 1.3(Fraleigh, 2014)

Suatu subhimpunan tidak kosong $H$ dari grup $G$ disebut subgroup dari $G$ jika $H$ membentuk grup terhadap operasi yang sama pada grup $G$.

Untuk mempermudah identifikasi suatu subgroup, diberikan Teorema berikut.

Teorema 1.4 (Romdhini, dkk., 2016)

Diketahui $G$ grup, $H \subseteq G, H \neq \emptyset$. Himpunan $H$ subgrup $G$ jika dan hanya jika $a b^{-1} \in H$ untuk setiap $a, b \in H$.

Dari suatu grup, setiap anggotanya mempunya orde, hal itu didefinisikan sebagai berikut.

Definisi1.5(Herstein, 1975)

Misal $(G, *)$ adalah sebarang grup. Misal $a$ adalah sebarang elemen dari $G$. Jika $m$ adalah bilangan bulat terkecil yang memenuhi $a^{m}=e$ ( $e$ adalah elemen identitas di $G$ ) maka m dikatakan sebagai orde dari $a$, dan dituliskan sebagai $|a|=m$

Teori graf merupakan pokok bahasan yang sudah tua usianya namun memiliki banyak terapan sampai saat ini. Graf digunakan untuk mempresentasikan objek-objek diskrit dan hubungan antara objek-objek tersebut. Berikut definisi tentang graf.

Definisi 1.4(Munir, 2010)

Graf didefinisikan sebagai pasangan $\operatorname{himpunan}(V, E)$ ditulis dengan notasi $G=(V, E)$, yang dalam hal ini $V$ 
adalah himpunan tidak kosong dari simpul-simpul dan $E$ adalah himpunan bagian dari $V \times V$.

Pada artikel ini, graf yang dibahas adalah graf sederhana saja, yakni graf tak berarah yang tidak memuat gelang dan sisi ganda. Graf tak berarah adalah graf dimana sisi $(v, w)=(w, v)$. Gelang adalah sisi berbentuk $(v, v)$, dan sisi ganda artinya pasangan $(v, w) \in E$ itu tunggal.

Graf mempunyai beberapa bentuk khusus diantaranya adalah graf bipartit. Lebih jelasnya diberikan definisi berikut.

Definisi 1.5(Munir, 2010)

Graf $G$ yang himpunan simpulnya dapat dipisah menjadi dua himpunan bagian $V_{1}$ dan $V_{2}$, sedemikian sehingga setiap sisi pada $G$ menghubungkan sebuah simpul di $V_{1}$ ke sebuah simpul di $V_{2}$ disebut graf bipartit dan dinyatakan sebagai $G\left(V_{1}, V_{2}\right)$.

Selain graf bipartit, terdapat juga graf multipartit yang merupakan perumuman dari graf bipartit. Graf ini dipartisi menjadi lebih dari dua partisi.

Definisi 1.6(Ma, dkk., 2014)

Graf k-partit (multipartit) adalah graf yang simpulnya dapat dipartisi ke dalam himpunan $k$ disjoint sehingga setiap dua simpul pada partisi tidak bertetangga.

Berikut penjelasan tentang graf khusus lainnya yaitu graf lengkap yang dijelaskan pada definisi berikut.

Definisi 1.7(Munir, 2010)

Graf lengkap adalah graf sederhana yang setiap simpulnya mempunyai sisi ke semua simpul lainnya.

Jenis graf khusus berikutnya adalah graf teratur, yang didefinisikan pada definisi berikut.

Definisi 1.8(Munir, 2010)

Graf yang setiap simpulnya mempunyai derajat yang sama disebut graf teratur. Dimana derajat dari simpul $v$ adalah jumlah semua sisi yang memuat $v$

Untuk bentuk graf khusus yang terakhir yaitu graf lingkaran, dijelaskan pada definisi berikut.
Definis 1.9(Munir, 2010)

Graf lingkaran adalah graf sederhana yang setiap simpulnya berderajat dua. Graf lingkaran dengan $n$ simpul dilambangkan dengan $C_{n}$.

\section{Metode}

Metode penelitian yang dilakukan adalah metode deduktif yaitu dengan membuat konjektur berdasarkan sifat-sifat yang sudah ada, kemudian konjektur akan dibuktikan secara deduktif.

\section{Hasil dan Pembahasan}

\subsection{Grup Quaternion dan subgrupnya}

Definisi 3.1.1(Irawan, 2015)

Grup Quaternion dengan operasi kali dinotasikan $\mathbb{Q}_{8}$, didefinisikan dengan

Dimana:

$$
\mathbb{Q}_{8}=\{1,-1, i,-i, j,-j, k,-k\}
$$

- 1. $a=a .1=a, \forall a \in \mathbb{Q}_{8}$

- $i . i=j \cdot j=k . k=-1$

- $i . j=k, j . i=-k$

-j. $k=i, k . j=-i$

- $k . i=j, i . k=-j$

atau dapat disajikan dalam tabel Cayley berikut

Tabel 3.1.1 Cayley dari $\mathbb{Q}_{8}$

\begin{tabular}{|c|c|c|c|c|c|c|c|c|}
\hline$\cdot$ & $\mathbf{1}$ & $-\mathbf{1}$ & $\boldsymbol{i}$ & $-\boldsymbol{i}$ & $\boldsymbol{j}$ & $-\boldsymbol{j}$ & $\boldsymbol{k}$ & $-\boldsymbol{k}$ \\
\hline $\mathbf{1}$ & 1 & -1 & $i$ & $-i$ & $j$ & $-j$ & $k$ & $-k$ \\
\hline$-\mathbf{1}$ & -1 & 1 & $-i$ & $i$ & $-j$ & $j$ & $-k$ & $k$ \\
\hline $\boldsymbol{i}$ & $i$ & $-i$ & -1 & 1 & $k$ & $-k$ & $-j$ & $j$ \\
\hline$-\boldsymbol{i}$ & $-i$ & $i$ & 1 & -1 & $-k$ & $k$ & $j$ & $-j$ \\
\hline $\boldsymbol{j}$ & $j$ & $-j$ & $-k$ & $k$ & -1 & 1 & $i$ & $-i$ \\
\hline$-\boldsymbol{j}$ & $-j$ & $j$ & $k$ & $-k$ & 1 & -1 & $-i$ & $i$ \\
\hline $\boldsymbol{k}$ & $k$ & $-k$ & $j$ & $-j$ & $-i$ & $i$ & -1 & 1 \\
\hline$-\boldsymbol{k}$ & $-k$ & $k$ & $-j$ & $j$ & $i$ & $-i$ & 1 & -1 \\
\hline
\end{tabular}

Dari tabel dapat dilihat bahwa $\mathbb{Q}_{8}$ bukan grup komutatif karena $i . j=k$ tapi $j . i=-k$.

Adapun untuk setiap subgrupnya antara lain:

1. Subgrup sejati adalah setiap subgrup kecuali grup itu sendiri, yaitu $S_{1}=$ 
$\{1,-1,-i, i\}, S_{2}=\{1,-1,-j, j\}, S_{3}=$ $\{1,-1,-k, k\}, S_{4}=\{1,-1\}$ dan $\{1\}$.

2. Subgrup trivial adalah subgrup yang terdiri dari grup itu sendiri dan identitasnya yaitu $\mathbb{Q}_{8}$ dan $\{1\}$.

3. Subgrup non-trivial adalah setiap subgrup kecuali grup itu sendiri dan identitasnya, yaitu $\quad S_{1}=\{1,-1,-i, i\} \quad, \quad S_{2}=$ $\{1,-1,-j, j\}, S_{3}=\{1,-1,-k, k\}, S_{4}=$ $\{1,-1\}$

Untuk subgrup yang digunakan lebih lanjut pada artikel ini adalah subgrup non-trivial. Berikut sifat yang menjelaskan tentang sifat komutatif dari subgrupnya.

Akibat 3.1.2 (Syarifudin \& Wardhana, 2019)

Setiap subgrup sejati dari grup quaternion adalah komutatif.

Sifat selanjutnya yang diperlukan adalah orde dari setiap elemen, berikut dipaparkan orde dari setiap elemennya pada tabel di bawah ini.

Tabel 3.1.2 orde elemen grup quaternion

\begin{tabular}{|c|l|l|l|l|l|l|l|l|}
\hline $\mathbb{Q}_{8}$ & 1 & -1 & $i$ & $-i$ & $j$ & $-j$ & $k$ & $-k$ \\
\hline Orde & 1 & 2 & 4 & 4 & 4 & 4 & 4 & 4 \\
\hline
\end{tabular}

Berikut disajikan beberapa definisi tentang graf koprima, graf non-koprima, graf commuting, graf non-commuting dan graf identitasnya serta bentuk-bentuknya.

\subsection{Graf koprima}

Graf koprima adalah representasi graf dari suatu grup hingga, grup dengan jumlah anggota berhingga, dengan sisinya dibentuk dari hubungan antara orde unsur-unsurnya.

Definisi 3.2.1(Ma, dkk., 2014)

Misalkan $G$ grup hingga, Graf koprima dari grup $G$ yang dinotasikan dengan $\Gamma_{G}$ adalah graf dengan simpul yang terdiri dari semua elemen dari $G$ dengan dua simpul berbeda $x$ dan $y$ dari $\Gamma_{G}$ dikatakan bertetangga apabila $(|x|,|y|)=1$.

Berikut bentuk graf koprima dari grup quaternion dan setiap subgrup non-trivialnya.

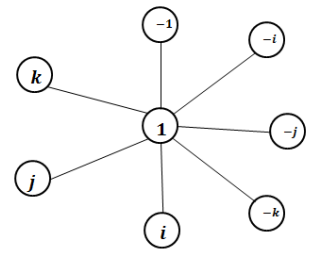

Gambar 3.2.1 Graf koprima dari grup quaternion

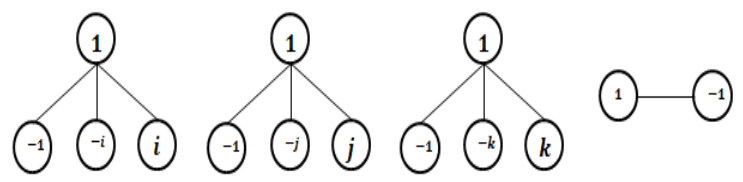

Gambar 3.2.2 Graf koprima dari subgrup quaternion

\subsection{Graf non koprima}

Definisi 3.3.1(Mansoori, dkk., 2016)

Misalkan $G$ suatu grup hingga. Graf non-koprima dari grup $G$ adalah graf yang himpunan simpulnya adalah $G \backslash\{e\}$ dengan dua simpul yang berbeda $u$ dan $v$ anggota $G$ dikatakan bertetangga apabila $(|\mathrm{u}|,|\mathrm{v}|) \neq$ 1. Graf koprima dari grup $G$ dinotasikan dengan $\overline{\Gamma_{\mathrm{G}}}$

Berikut bentuk graf non-koprima dari grup quaternion dan setiap subgrup non-trivialnya.

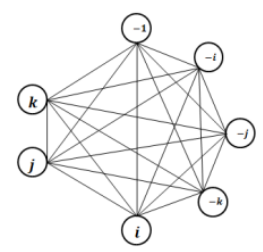

Gambar 3.3.1Graf non-koprima dari grup quaternion

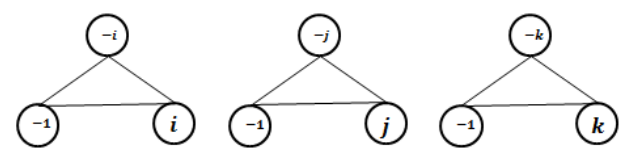

Gambar 3.3.2Graf non-koprima dari subgrup quaternion

\subsection{Graf Commuting}

Definisi 3.4.1 (Nawawi, dkk., 2012)

Misalkan $G$ adalah grup hingga dan $X$ adalah subhimpunan tak kosong dari $G$. Graf commuting $C(G, X)$ adalah graf dengan $X$ sebagai himpunan simpul dan dua elemen berbeda di $X$ bertetangga jika 
hanya jika keduanya adalah elemen yang saling komutatif di $G$. Jika tidak dinyatakan, maka $X=G$.

Berikut bentuk graf commuting dari grup quaternion dan setiap subgrup non-trivialnya.

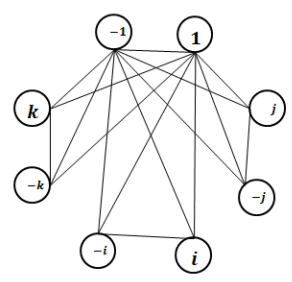

Gambar 3.4.1Graf commuting dari grup quaternion
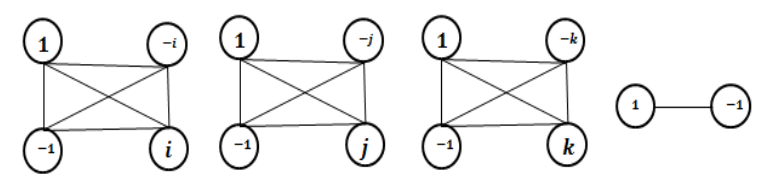

Gambar 3.4.2Graf commuting dari subgrup quaternion

\subsection{Graf non-commuting}

Berkebalikan dengan graf commuting, graf noncommuting adalah graf dari suatu grup dimana dua elemen dari grup bertetangga jika keduanya tidak komutatif.

Definisi 3.5.1 (Abdollahi, dkk., 2006)

Misalkan $\mathrm{G}$ grup tidak komutatif dan subgrup $\mathrm{Z}(\mathrm{G})=$ $\{x \in G \mid x g=g x \forall g \in G\}$ adalah center dari G. Graf non-commuting adalah sebuah graf komplemen dari graf $C(G, X)$, dimana simpul-simpulnya merupakan himpunan dari $\mathrm{G} \backslash \mathrm{Z}(\mathrm{G})$ dengan dua simpul $\mathrm{x}$ dan $\mathrm{y}$ dikatakan bertetangga jika hanya jika $\mathrm{x} . \mathrm{y} \neq \mathrm{y} \cdot \mathrm{x}$. dinotasikan $\overline{C(G, X)}$. Dimaan $X=G \backslash Z(G)$.

Berikut bentuk graf non-commuting dari grup quaternion dan setiap subgrup non-trivialnya.

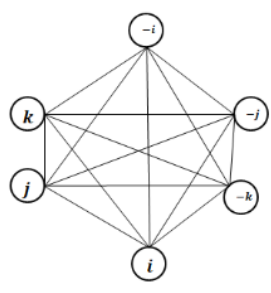

Gambar 3.5.1Graf non-commuting dari grup quaternion

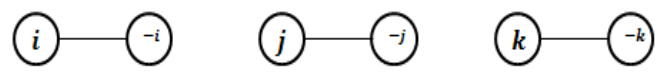

Gambar 3.5.2 Graf non-commuting dari grup quaternion

\subsection{Graf identitas}

Definisi 3.6.2 (Kandasamy dan Smarandache, 2009) Misalkan G suatugruphingga. Graf identitas dari grup $G$ adalah graf yang simpulnya adalah semua elemen grup $G$. Dua simpul yang berbeda $u$ dan $v$ bertetangga jika hanya jika $u \cdot v=v \cdot u=e$ dan setiap elemen grup terhubung langsung dengan elemen identitas pada grup. Graf identitas ini dinotasikan dengan $I(G)$.

Berikut bentuk graf identitas dari grup quaternion dan setiap subgrup non-trivialnya.

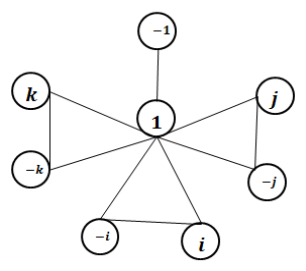

Gambar 3.6.1Graf identitas dari grup quaternion
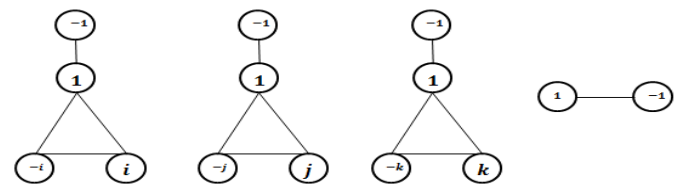

Gambar 3.6.2Graf identitas dari subgrup quaternion

Berdasarkan pengamatan beberapa graf, maka dapat diperoleh beberapa sifat dari graf khusus pada grup quaternion, mengikuti beberapa teorema berikut:

Teorema 3.1Jika suatu graf $G$ merupakan graf lingkaran lingkaran maka graf $G$ adalah graf teratur 


\section{Bukti.}

Berdasarkan definisi graf lingkaran mudah dilihat bahwa graf tersebut simpulnya mempunyai derajat yang sama yaitu 2 .

\section{Bentuk graf khusus dari grup quaternion}

Teorema 3.2Misalkan $\mathbb{Q}_{8}$ adalah grup quaternion maka graf koprima dari $\mathbb{Q}_{8}$ adalah graf bipartit lengkap.

\section{Bukti.}

Misalkan $\mathbb{Q}_{8}$ adalah grup quaternion. Partisi grup quaternion menjadi 2 partisi yaitu $V_{1}=\{1\}$, dan $V_{2}=$ $\{-1, i,-i, j,-j, k,-k\}$. Mudah dilihat orde dari grup quaternion pada Tabel 2.2 sehingga untuk setiap $x, y \in V_{2}$ diperoleh $(|x|,|y|)=2 \neq 1$, jadi $x$ dan $y$ tidak bertetangga. Karena $|e|=1$ maka untuk sebarang $v \in V_{2}$ sehingga berlaku $(|e|,|v|)=1$. Jadi $e$ bertetangga dengan $v$ sehingga bentuk graf koprima dari grup quaternion adalah bipartite lengkap.

Akibat 3.3 Jika $\mathbb{Q}_{8}$ adalah grup quaternion dan $H$ adalah subgrup nontrivial maka graf koprima dari $H$ adalah graf bipartit lengkap

Teorema 3.3 Jika $\mathbb{Q}_{8}$ adalah grup quaternion maka graf non-koprima dari $\mathbb{Q}_{8}$ adalah graf lengkap dan teratur.

\section{Bukti.}

Misalkan $\mathbb{Q}_{8}$ adalah grup quaternion. Mudah dilihat orde dari setiap elemen dari grup quaternion pada Tabel 2.2, sehingga untuk setiap $x, y \in \mathbb{Q}_{8}$ berlaku $(|x|,|y|) \neq 1$. Akibatnya setiap $x, y \in \mathbb{Q}_{8}$ saling bertetangga. Dengan demikian, setiap simpulnya mempunyai sisi ke semua simpul lainnya dan setiap simpulnya mempunyai derajat yang sama sehingga bentuk graf non-koprima dari grup quaternion adalah graf lengkap dan teratur.

Akibat 3.4 Jika $\mathbb{Q}_{8}$ adalah grup quaternion dan $H$ adalah subgrup nontrivial maka graf non-koprima dari $H$ adalah graf lengkap dan teratur.

Teorema 3.5 Jika $\mathbb{Q}_{8}$ adalah grup quaternion maka graf commuting dari $\mathbb{Q}_{8}$ adalah graf multipartit.

\section{Bukti.}

Misalkan $\mathbb{Q}_{8}$ adalah grup quaternion, $\mathbb{Q}_{8}$ adalah salah satu grup non-komutatif tetapi mudah kita lihat bahwa subgrup non-trivialnya komutatif dan mempunya 4 subgrup non-trivial, karena satu subgrup adalah anggota dari subgrup lainnya maka kita peroleh 3 partisi sehingga bentuk graf commuting dari $\mathbb{Q}_{8}$ adalah graf multipartit.

Teorema 3.6Misalkan $\mathbb{Q}_{8}$ adalah grup quaternion maka graf non-commuting dari $\mathbb{Q}_{8}$ adalah graf lengkap dan teratur .

Bukti.

Misalkan $\mathbb{Q}_{8}$ adalah grup quaternion dengan $\mathrm{Z}\left(\mathbb{Q}_{8}\right)=$ $\{1,-1\}$. Mudah dilihat bahwa $\mathbb{Q}_{8} / Z\left(\mathbb{Q}_{8}\right)$ adalah nonkomutatif sehingga setiap simpulnya saling terhubung satu sama lain akibatnya setiap simpulnya mempunyai sisi ke semua simpul lainnya dan setiap simpulnya mempunyai derajat yang sama sehingga bentuk graf non-commutingdari grup quaternion adalah graf lengkap dan teratur.

Akibat 3.7 Jika $\mathbb{Q}_{8}$ adalah grup quaternion dan $H$ adalah subgrup non-trivial maka graf non-commuting dari $H$ adalah graf lengkap dan teratur.

Teorema 3.8 Jika $\mathbb{Q}_{8}$ adalah grup quaternion maka graf identitas dari $\mathbb{Q}_{8}$ adalah graf multipartit.

\section{Bukti.}

Misalkan $\mathbb{Q}_{8}$ adalah grup quaternion, seperti yang terlihat pada tabel 2.1 mudah terlihat bahwa bentuk graf graf identitas dari $\mathbb{Q}_{8}$ adalah graf multipartit karena tentu setiap elemen 1 bertetangga dengan setiap elemen pada $\mathbb{Q}_{8}$ selanjutnya berdasarkan sifat identitasnya kita ketahui bahwa $-k \cdot k=k .-k=$ $-i . i=i .-i=-j . j=j .-j=1$.

\section{Kesimpulan dan Saran}

Adapun beberapa kesimpulan dari artikel ini sebagai berikut.

1. Bentuk graf koprima dari grup quaternion adalah graf bipartit lengkap, begitupun untuk setiap subgrupnya.

2. Bentuk graf non-koprima dari grup quaternion adalah graf lengkap dan teratur, begitupun untuk setiap subgrupnya.

3. Bentuk graf commuting dari grup quaternion adalah graf multipartit sedangkan setiap subgrupnya berbentuk graf lengkap dan teratur. 
4. Bentuk graf non-commuting dari grup quaternion adalah graf lengkap dan teratur, begitupun untuk setiap subgrupnya.

5. Bentuk graf identitas dari grup quaternion adalah graf multipartit.

Saran dalam penelitian ini yaitu adanya studi lanjutan tentang sifat-sifat graf lainnya dari grup quartenion maupun grup-grup lainnya.

\section{Daftar Pustaka}

Abdollahi, A., Akbari, S., and Maimani, H. (2006). Non-commuting Graph of a Group. Journal of Algebra: 468-492.

Fraleigh, J. B. (2014). A First Course in Abstract Algebra Seventh Edition. United States of America: Pearson Education Limited.

Herstein, I. N. (1975). Topics In Algebra, Second Edition. Prentice-Hall, Inc, United: States of America.

Irawan, Muh.. (2015). Quaternion and it's properties, Jurnal Matematika Statistika dan Analisis Vol 3 No 1.

Juliana, R., Wardahan, I. G. A. W., Switrayni, N. W., Irwansyah, I. (2020). Coprime Graph Of Integers Modulo N Group And Its Subgroups. Journal of Fundamental Mathematics and Applications (JFMA) 3 (1), 15-18

Kandasamy, W. B., Smarandache, F. (2009). Group As Graph. Romania: Editura Cuart.

Ma X., H. Wei and L. Yang. (2014). The coprime graph of a group. Int. J. Group Theory. 3(3): 13-23.

Mansoori, F., Erfanian A., and Tolue, B. (2016). Noncoprime Graph of a Finite Group. AIP Conference Proceedings.

Masriani, M., Juliana, R., Syarifudin, A.G., Wardhana, I. G. A. W, Irwansyah, I., Switrayni, N. W. (2020). Some Result Of Non-Coprime Graph Of Integers Modulo N Group For N A Prime Power. Journal of Fundamental Mathematics and Applications (JFMA) 3(2), 107-111.

Misuki, W. U., Wardhana, I. G. A. W., Switrayni, N. W., Irwansyah, I. (2021). Some Results Of
Non-Coprime Graph Of The Dihedral Group D2n For N A Prime Power. AIP Conference Proceedings 2329 (1), 020005.

Munir, Rinaldi. (2010). Matematika Diskrit. Bandung:Informatika Bandung.

Nurhabibah, N., Syarifudin, A. G., Wardhana, I. G. A. W. (2021). Some Results of The Coprime Graph of a Generalized Quaternion Group $Q_{4 n}$. InPrime: Indonesian Journal of Pure and Applied Mathematics 3 (1), 29-33.

Nawawi, A., Rowley, P. (2012). On Commuting Graph for Element of Order 3 in Symetry Groups. Manchester: The MIMS Secretary.

Romdhini, M. U., Irwansyah., and Switrayni, N. W. (2016). Struktur Aljabar. Mataram: Universitas Mataram.

Syarifudin, A.G., Nurhabibah, N., Malik, D. P., Wardhana, I. G. A. W (2021). Some characterizatsion of coprime graph of dihedral group $D_{2 n}$. Journal of Physics: Conference Series 1722 (1), 012051.

Syarifudin, A.G., Wardhana, I. G. A. W (2019). Beberapa Sifat Grup Kompleks dan Grup Quaternion. 3 ${ }^{\text {rd }}$ ELPSA Conferences: 48-54. 